\title{
Trends in maternal mortality in a tertiary care hospital
}

\author{
K. P. Mohana Sundari*, R. Dheeba Jayanthi, Bharathi Ramasamy
}

Department of Obstetrics and Gynecology, Government Mohan Kumaramangalam Medical College, Salem, Tamil Nadu, India

Received: 26 September 2016

Accepted: 07 October 2016

\section{*Correspondence:}

Dr. K. P. Mohana Sundari,

E-mail: m72sundari@yahoo.in

Copyright: (C) the author(s), publisher and licensee Medip Academy. This is an open-access article distributed under the terms of the Creative Commons Attribution Non-Commercial License, which permits unrestricted non-commercial use, distribution, and reproduction in any medium, provided the original work is properly cited.

\section{ABSTRACT}

Background: To analyze the trends in maternal mortality in a tertiary hospital in Salem, Tamil Nadu.

Methods: Design of the study was retrospective. Records of all maternal deaths occurring for the past 3 years from January 2013-December 2015 were studied and various factors analyzed and compared.

Results: The maternal mortality rate ranged between 559-802/ 1,00,000 live births in our study. The majority of deaths were in the age group between 21-25 yrs. The majority of deaths in 2013 were due to hemorrhage (19.5\%) followed by cortical venous thrombosis (17.6\%), hypertensive disorders (14.6\%). But in 2014 and 2015 hypertensive disorders were the common cause of death, [2014 (23\%), 2015 (26.78\%)] followed by hemorrhage (2014-12.8\%, $2015-17.5 \%)$ and sepsis (2014-20.5\%, 2015-12.5\%).

Conclusions: Majority of maternal deaths can be prevented by adopting improved standards in early identification of preeclampsia, anemia and its management and early referral. Routine iron and folic acid supplementation to be done in an effective way. Proper antenatal care, emergency obstetrics care and routine audits are very much essential to decrease the maternal mortality as well as to know the trends of maternal deaths to develop subsequent management protocols.

Keywords: Maternal mortality, Changing trends, Hypertensive disorders

\section{INTRODUCTION}

Maternal mortality is a vital index of the effectiveness of obstetrics service prevailing in a country. By country wise India has the largest maternal death $(63,000 /$ year $)$. Maternal death is a very tragic event and it is still the leading cause of death in women in reproductive age group. In India approximately 28 million women experience pregnancy and 26 million women have live birth. ${ }^{1}$ Millennium Development Goal 5(MDG 5) aims at reducing $75 \%$ of MMR over a period of $1990-2015 .^{2}$ In 2008 there was an estimated 3,58,000 maternal death in the world with the MMR 260/1,00,000 live birth. ${ }^{3}$

According to MDG India is making progress but it is very slow and not on track. So this study is an attempt to review the various causes of maternal death over a period of time, to identify the etiological factors and ways and means to prevent them. In order to reduce the MMR the following important issues needs to be concentrated like improving literacy rate in women and rise in contraceptive practice because both strongly correlate with decline in MMR. The MMR in India is 167 in 20112013 and likely to reach 140 by 2015 .

\section{METHODS}

Study design: This study was conducted in the department of obstetrics, GMK Medical College Salem. Hospital records of all the maternal deaths for 3 years from January 2013-december 2015 were studied and analysed and compared. Every maternal death was 
scrutinized and various aspects likely to be related to death such as age, locality, parity, condition of women at admission, cause of death.

\section{RESULTS}

The maternal death mostly occurred in the age group of $21-25$ years in all the three years [(2013-43.9\%, 2014$48.7 \%, 2015-64.2 \%)]$. In 2013 comparatively there was a higher incidence of death in women $>30$ yrs $(24.3 \%)$ which has reduced subsequently .Over the years the deaths from urban area has reduced considerably from $14.63 \%$ in 2013 to $1.78 \%$ in 2015 because of increased health awareness among urban people whereas rural areas deaths are increasing. Deaths were maximum in primigravida in 2013 (43.9\%) whereas in 2014 and 2015 maximum deaths occurred in gravida 2 (2014-41\%, 2015$48.2 \%$ ). In gravida 3 and above the deaths were high in 2013 but it has come down in 2014 and 2015 probably due to the awareness of family planning methods and less number of women becoming pregnant after second child.

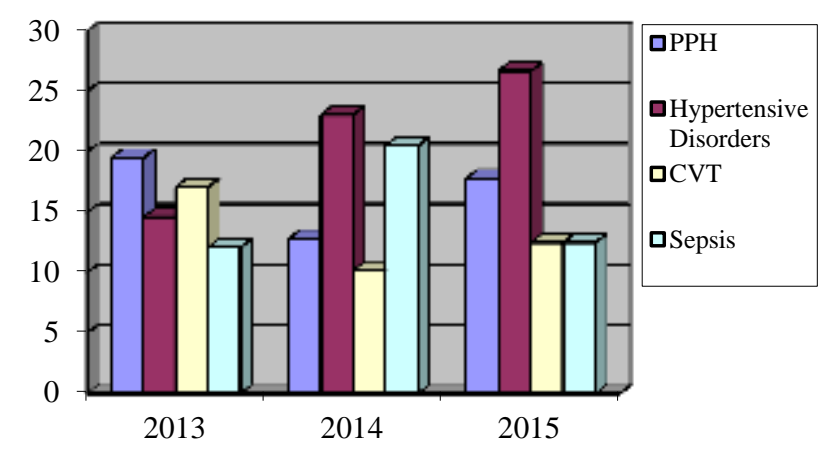

Figure 1: Trends in maternal mortality.

The usage of 108 ambulances for transport has increased from $75 \%$ in 2013 to $87.5 \%$ in 2015 . The referral rate has increased over the years from $75.6 \%$ in 2013 and $79.5 \%$ in 2014 to $94.6 \%$ in 2015 . In 2013 the largest numbers of referrals were from Government hospitals $45.6 \%$ and Medical College $9.6 \%$ and only $12.9 \%$ cases were referred from PHC. In 2014 also the referral pattern was comparable to 2013 but in 2015 there was more number of referrals from PHC (26.4\%). There was increasing bad case referral at last minute from adjacent two new medical colleges $(20.7 \%)$ which is the main cause for the increase in maternal death during 2015. When analyzing the death with regard to the gestational age, deaths were mostly during term, whereas the death following abortion has considerably reduced over the years $7.3 \%$ in 2013, $2.56 \%$ in $2014,1.78 \%$ in 2015 . Institutional deliveries were $94 \%$ in all the three years.

There was increasing number of deaths in women undergoing LSCS $21 \%$ in 2013, $47 \%$ in $2014,62 \%$ in 2015. Six deaths in 2015 were due to internal bleeding, so the skill of junior doctors and postoperative care has to be improved. Around $50 \%$ of the patients were admitted in poor condition in 2013 and 2014 but in 2015 64.2\% were admitted in poor condition which could be the reason for increase in maternal death in 2015. Anemia has been a significant co-morbid factor in all the three years $60.9 \%$ in $2013,56.45$ in 2014 and $53.5 \%$ in 2015 . So there is not much difference in the reduction in anemia in pregnant women.

Table 1: Characteristics of maternal deaths.

\begin{tabular}{|c|c|c|c|c|c|c|}
\hline & \multicolumn{2}{|c|}{2013} & \multicolumn{2}{|c|}{2014} & \multicolumn{2}{|c|}{2015} \\
\hline & No. & $\%$ & No. & $\%$ & No. & $\%$ \\
\hline \multicolumn{7}{|l|}{ Age } \\
\hline$<20$ & 3 & 7.31 & 6 & 15.3 & 6 & 10.7 \\
\hline $21-25$ & 18 & 43.9 & 19 & 48.7 & 36 & 64.2 \\
\hline $26-29$ & 10 & 24.3 & 8 & 20.5 & 6 & 10.7 \\
\hline$>30$ & 10 & 24.3 & 6 & 15.3 & 8 & 14.2 \\
\hline \multicolumn{7}{|l|}{ Locality } \\
\hline Rural & 35 & 85.36 & 37 & 94.8 & 55 & 98.21 \\
\hline Urban & 6 & 14.63 & 2 & 5 & 1 & 1.78 \\
\hline \multicolumn{7}{|l|}{ Parity } \\
\hline Primi & 14 & 35.89 & 18 & 43.9 & 16 & 28.5 \\
\hline $\mathrm{G} 2$ & 16 & 41 & 7 & 17.07 & 27 & 40.2 \\
\hline $\begin{array}{l}\text { G3 and } \\
\text { above }\end{array}$ & 9 & 22 & 16 & 38 & 13 & 23.2 \\
\hline \multicolumn{7}{|c|}{ Gestational age } \\
\hline Term & 21 & 53.8 & 24 & 58.5 & 33 & 58.92 \\
\hline \multicolumn{7}{|l|}{ Transport } \\
\hline Ambulance & 29 & 74.3 & 31 & 75.6 & 49 & 87.5 \\
\hline Self & 10 & 25.64 & 10 & 24.39 & 7 & 12.5 \\
\hline \multicolumn{7}{|l|}{ Referral } \\
\hline Referral & 33 & 80.48 & 29 & 74.35 & 53 & 94.6 \\
\hline No referral & 8 & 20.5 & 10 & 24.3 & 3 & 5.37 \\
\hline \multicolumn{7}{|l|}{ Referral } \\
\hline PHC & 6 & 19.3 & 4 & 12.4 & 14 & 26.4 \\
\hline $\mathrm{GH}$ & 22 & 70.96 & 14 & 45.6 & 23 & 43.3 \\
\hline $\mathrm{MC}$ & 1 & 3.22 & 3 & 9.6 & 11 & 26.7 \\
\hline Private & 2 & 6.45 & 8 & 25.8 & 5 & 19.43 \\
\hline \multicolumn{7}{|l|}{ Booking } \\
\hline Booked & 38 & 92.6 & 37 & 94.8 & 55 & 98.2 \\
\hline Unbooked & 3 & 7.31 & 2 & 5.1 & 1 & 1.78 \\
\hline \multicolumn{7}{|c|}{ Place of delivery } \\
\hline Institution & 36 & 94.7 & 36 & 94.7 & 47 & 94 \\
\hline Home & 2 & 5.2 & 2 & 5.2 & 3 & 6 \\
\hline \multicolumn{7}{|c|}{ Root of delivery } \\
\hline $\begin{array}{l}\text { Labour } \\
\text { Naturals }\end{array}$ & 16 & 42.1 & 24 & 63.15 & 17 & 34 \\
\hline LSCS & 18 & 47.3 & 8 & 21.05 & 31 & 62 \\
\hline \multicolumn{7}{|c|}{ Admission Status } \\
\hline Stable & 20 & 48.78 & 20 & 51.28 & 20 & 35.7 \\
\hline Poor & 21 & 51.21 & 19 & 48.71 & 36 & 64.28 \\
\hline
\end{tabular}

In 2013 the maximum cause of death was PPH (19.5\%) followed by CVT (17.07\%) and hypertensive disorders (14.6\%). In 2014 hypertensive disorders (23\%) were the commonest cause followed by sepsis (20.5\%), PPH (12.8\%). In 2015 again hypertensive disorders (26.78\%) 
were the common cause followed by hemorrhage (17.85\%), sepsis (12.5\%), CVT (12.55). In $17.85 \%$ due to hemorrhage that is out of 10 cases 5 cases were due to internal bleeding, 3 due to atonic PPH, 2 due to Abruption and DIC. So death due to atonic PPH has reduced considerably. Comparing all the three years deaths due to Hemorrhage is coming down and deaths due to hypertensive disorders in pregnancy is increasing gradually. Booking has improved from $92.6 \%$ in 2013, $94.8 \%$ in 2014 to $98.2 \%$ in 2015.During the last years the MMR in our college ranged between 559 to 802 per $1,00,000$ live births. There was increasing death in 2015 mainly due to late referrals from the medical colleges. $64.2 \%$ of them were in poor general condition at the time of admission.

Table 2: Cause of death.

\begin{tabular}{|lllllll|}
\hline & 2013 & \multicolumn{3}{l}{2014} & \multicolumn{2}{l}{2015} \\
$\begin{array}{l}\text { Cause of } \\
\text { death }\end{array}$ & No. & $\%$ & No. & $\%$ & No. & $\%$ \\
\hline PPH & 8 & 19.5 & 5 & 12.8 & 10 & 17.8 \\
\hline $\begin{array}{l}\text { Hypertensive } \\
\text { disorders }\end{array}$ & 6 & 14.6 & 9 & 23.07 & 15 & 26.7 \\
\hline CVT & 7 & 17.07 & 4 & 10.2 & 7 & 12.5 \\
\hline Sepsis & 5 & 12.1 & 8 & 20.5 & 7 & 12.5 \\
\hline
\end{tabular}

\section{DISCUSSION}

The MMR in our study ranged between 559-802 per $1,00,000$ live birth which is comparable to studies done in other tertiary institutions. ${ }^{4}$ Pathak et al study reported MMR of 428-869.6/ 1,00,000 live births due to large number of referral cases. Most mothers died in the age group between 21-25 years in all three years in our study which is comparable to study done by pathak et al. ${ }^{5}$ In 2013 maximum death occurred in primi women which are comparable to study done by Pathak et al at BSMC Hospital Bankura district. Whereas in 2014, 2015 more death were in gravida which is comparable to same study done by Pathak et al at Eden Hospital Kolkata.

The NRHM through JSY scheme encourages rural women for institutional delivery still home deliveries were reported in $6 \%$ of cases in all the three years. ${ }^{6}$ In our study the booking status is throughout high and is increasing. In our study the booking rate is very high ranging between $92.6 \%$ to $98.2 \%$ which is not comparable to studies done by Paul et al and Pathak et al where the booking rate itself very low. ${ }^{4,5}$

Anemia was significant comorbid factor in our study which is comparable to study done by Paul et al but the percentage of anemia is very high in our study. In our study hemorrhage was the commonest cause of death in 2013 whereas hypertension disorders was the commonest cause of death in2014, 2015 which is comparable to study done by Paul et al and also comparable to study done by Konar et al. ${ }^{7}$
Although use of magnesium sulphate and early termination of pregnancy has led to improvement in the scenario of eclampsia, early diagnosis of PIH needs to be emphasized to prevent deaths due to preeclampsia. The decrease in death due to hemorrhage is mainly attributed to SBA training to all staff nurses, VHNS at PHC and GH level. Sepsis was reported in $12.1 \%-20.5 \%$ of our cases which is comparable to other studies which showed $13.75 \%$ of death due to sepsis. ${ }^{8}$ The need for Antibiotics and infection control practices are to be strictly followed to reduce death due to sepsis. ${ }^{6}$ The tertiary care hospitals regrettably receive usually complicated cases through referral and mostly admitted only during the terminal stage of their illness. This may be the reason for such a high report of MMR in our college in 2015.

\section{CONCLUSION}

In confidential review of maternal death we have to find out the possible levels in prevention of death and concentrate in strengthening the areas where lacunae are found. Although we have empowered our SBA to give magnesium sulphate and excellent AMTSL training still the early detection of hypertension is delayed. So the number of visits in the third trimester needs to be increased at least once a week for early detection of preeclampsia. Early correction of anemia and health education on the importance of IFA tablets and contraception and the imminent symptoms of preeclampsia will reduce the maternal mortality to greater extent. At the tertiary care level proper history taking, timely decision, judicious use of IV drugs, IV fluids and blood products will help in reducing the death. The hospital based mortality figures actually do not reflect the real picture in the community but it helps us to provide a thorough assessment of underlying cause of death and the contributing factors as well as to evaluate the trend in maternal deaths so that we may plan an action protocol to correct the deficits, concentrate more on the skills to be provided to the health care personnel.

\section{Funding: No funding sources \\ Conflict of interest: None declared}

Ethical approval: The study was approved by the Institutional Ethics Committee

\section{REFERENCES}

1. National Rural Health Rural Health Mission: Frame work for implementation 2005-2012, New Delhi.

2. United Nations Millennium Development goals. Available at www.un.org/millineumgoals. Accessed on 20 February 2016.

3. Maternal mortality in India Special bulletin, Office of the Registrar. General of India, New Delhi.

4. Pal A, Ray P, Hazra S, Mondal TK. Review of changing trends in maternal mortality in a rural medical college in West Bengal. Jobstr Gynecol India. 2005:55(6):521-4. 
5. Pathak D, Chakraborty B, Goswami S, Adhikari S. Changing trends of maternal mortality: A comparative study. J Obstr Gynae India. 2011;61(2):161-5.

6. Mohanasundari KP, Padma PR, Subathra. Maternal mortality:analysis of causes and preventable factors. Int J Reprod Contracept Obstet Gynecol. 2016;5(6):1719-21.

7. Konar H, Chakraborty AB. Maternal mortality: a FOGSI study (Based on Institutional Data). J Obst Gynecol. 2013;63(2):88-95.
8. Khamathem PD, Chanam MS. Maternal Mortality and its causes in a Tertiary Center. J Obst Gynecol. 2012;62(2):168-71.

Cite this article as: Sundari KP, Jayanthi RD, Ramasamy B. Trends in maternal mortality in a tertiary care hospital. Int J Reprod Contracept Obstet Gynecol 2016;5:3659-62. 